\title{
Electrical Breakdown in a Solid Dielectric.
}

TT is now well known that if we have two spherical electrodes in a gas, then in certain cases, over a very wide range of the distance between them, the disruptive voltage can be determined with great accuracy. In computing this voltage, it is necessary to know first the nature of the gas and its temperature and pressure; secondly, the radii of the electrodes and the distance between them; and thirdly, the electric strength of the gas.

The only problem that is laborious and difficult is the computation of the maximum electric stress between the electrodes. When the electrodes are equal, these values can be found from tables well known to electrical engineers. For example, when the electrodes are each one inch in diameter, the disruptive voltage in air can be computed with at least a one per cent accuracy at distances varying from one-tenth of an inch to three inches, the corresponding voltages varying from about 10,000 volts to 50,000 volts. When the spheres are closer together than a tenth of an inch, other physical factors have to be taken into account. Everyday experience seems to show that there is a minimum sparking potential which is about 350 volts in air at ordinary atmospheric pressure and temperature.

The early experimenters, only having a few thousand volts available, were naturally unable to find any simple law connecting sparking voltage and distance. Kelvin, however, in his Reprint of Papers, pointed out so far back as 1860 that if we regarded the maximum electric stress as the determining factor, then it was 'most probable' that the numbers obtained in this way at higher voltages would be found to be sensibly constant, a surmise which has been rigorously proved in recent years by electricians.

With electrodes in a gas, there are three cases which need to be considered separately. First, when they are very close together; secondly, for distances apart up to about three diameters of either electrode; and thirdly, for greater distances when coronæ form before the breakdown discharge occurs. It is very easy to calculate in the last case when the corona appears.

In the Journal of the Franklin Institute for Decem. ber, P. H. Moon and A. S. Noreross prove that in a solid dielectric there seem to be three different physical causes that lead to its disruption by electric stress. The experiments were made on the lead glass of the approximately spherical bulbs of flasks. Mercury inside the flask formed one electrode, and it was immersed in a bath of mercury which forms the other electrode. This arrangement gets rid of the edge effect. All the tests were made with direct-current voltage obtained either from a hundred kilovolt kenotron set or a 4000 volt motor generator set.

It was found, first, that for low temperatures and for low values of the thickness, the relation connecting the breakdown voltage with the thickness of the glass is a linear one. Secondly, for higher temperatures and greater thicknesses, the breakdown voltage is no longer independent of the temperature but decreases as the temperature is raised. Finally, when the temperature is raised above $150^{\circ} \mathrm{C}$., the effect of temperature becomes much more pronounced and we reach the region of thermal instability which has been much studied by electricians. Tests with sodium. lime glass give similar results. Apparently there is no connexion between resistivity and breakdown in the disruptive region. Messrs. Moon and Norcross consider that there are three distinct mechanisms of breakdown, the one that actually takes place depending on the temperature, thickness, and constants of the material.

\section{Transport of Stones by Attached Seaweed.}

$\mathrm{M}^{\mathrm{R}}$. SYMINGTON GRIEVE directed attention to I the ocean transport of stones through the buoyancy of attached seaweed, with their consequent piling up as a stony beach where obstacles intercepted the ocean currents, in a paper in the Transactions of the Botanical Society of Edinburgh, vol. 14, pt. 2 (1882). This paper is reprinted in the Trans. and Proc. Bot. Soc., vol. 30, Part 2, 1929, together with further papers which give results of additional observations by the author since that time. Charles Darwin discusses in "The Voyage of the Beagle" the transport of stones to Keeling Island and other atolls, through their attachment in the roots of floating trees, and it is interesting to learn that shortly before his death (Mar. 22, 1882) he wrote to Mr. Symington Grieve from Down a brief note that indicated his interest in the subject, in which he states that he had "long known that stones were transported by floating Fuci"

Probably almost every naturalist who reads these interesting papers will recall some observation from his own experience which might have enlightened him as to the buoyancy added to stones by the canopy of attached seaweed, but it has been left to the author to realise tho significance such an apparently incidental occurrence may have, both in building up beaches of water-worn rocks, in contributing to the erosion of the cliff surface by its bombardment by Fucus-transported missiles in the waves, and even in contributing to the dislodging of massive masonry exposed to the waves and which, in time, has become covered with a canopy of seaweed. Around the British Isles the seaweeds that contribute most in giving buoyancy to the stones on which they grow are Fucus vesiculosus and Fucus (Ascophyllum) nodosus; to a lesser extent Fucus serratus and Chorda filum.

The author points out that the shape of the stone and the extent of the surface it exposes for the growth of the seaweed will be factors of importance in determining whether it is lifted from its bed by the tide, as also will be the amount of growth of the seaweed and the height of the water above it when under the influence of this tidal scour. He has noted stones with seaweed attachment drifting along the bottom of the tide, so that the stones left a grooved trail on the bottom. In the earlier paper it was pointed out how such a trail may be left on the sand or mud as the tide recedes, an alternative suggestion thus arising for some of the 'reptilian marks' or 'ripple marks' described for ancient or modern beaches.

The author also raises the question as to whether the sargasso seaweed, composed of the two species Sargassum vulgare and S. bacciferum, as it floats away from its breeding places upon the shores of the islands of Martinique, Guadeloupe, and Dominica, may not carry with it stones on its journey in the Caribbean Sea or the Atlantic or Pacific Oceans. The late Prof. James Chilton directed attention, in the Transactions of the New Zealand Institute (vol. 56, pp. 523-524), to the habit of the free-swimming larvæ of an ascidian of attaching themselves to pebbles, which are thus lifted from gravel beds so that, in stormy weather, they are thrown up on the beach. 